\title{
Theory of Change: An Approach to Improve Access to Medicines in Low and Middle-Income Economies
}

\author{
Mohammad Bashaar*1 and Tafseera Hashemi ${ }^{2}$ \\ ${ }^{1}$ Health Policy Analyst, SMART Afghan International Trainings and Consultancy, Shahri Naw, District 4, Kabul, Afghanistan \\ ${ }^{2}$ Faculty of Biology, Kabul University, Kabul, Afghanistan \\ *Corresponding Author: Mohammad Bashaar, Health Policy Analyst, SMART Afghan International Trainings and Consultancy, Shahri \\ Naw, District 4, Kabul, Afghanistan.
}

Received: August 22, 2019; Published: September 26, 2019

DOI: 10.31080/ASMS.2019.03.0420

\begin{abstract}
Regardless of recognition and application of the theory of change approach in the social sector, little is known about the extent to which it has been used in the design and evaluation of programs and projects related to access to medicines. The barriers towards access to medicines by using TOC, along with their strategies, outcomes, and impact were examined. We used TOC with the impact "to increase ATM." Through this process, different components of TOC were analyzed. Barriers to ATM were elaborated, which laid the foundation for the change. Outputs of the program were discussed at each level and strategies were identified for the better implementation of ATM intervention. It was found that an increase in physical, financial and social resources helped in establishing a sustainable healthcare system and guarantee universal healthcare coverage. In addition, there was an improvement in access to medicines for poor and underserved people and improvement in health outcomes for the marginalized population with the decrease in health disparities. It is urged that researchers evaluate complex interventions by employing this approach. To ensure the desired outcomes and ensure access to medicine for all, the stakeholders (state, non-state actors, pharmaceutical companies, policymakers, and donors) should invest resources and do a critical evaluation of programs for access to medicines.
\end{abstract}

Keywords: Access To Medicines; Theory Of Change; Affordability; Policy

\section{Background}

Access to Medicine (ATM) is a constraint and a challenge to sustainable health, despite international approaches [1]. This constraint may / may not have slowed progress at the strategic level in developed settings, but it surely has affected the poor and vulnerable patients in low and middle income settings.

The access to medicines (ATM) is a core component of sustainable healthcare system but is still relegated to the literature in many countries. The evidence unfortunately lacks research in health system components affecting priority policy areas like ATM. There is recognition that varied aspects of ATM are interconnected, and without consideration of the interrelated parts and how they affect each another, policies are ineffective in improving health outcomes because these are unable to face the barriers. There is a need to take a systems perspective to better understand how to intervene and the effect of intervention for ATM [2].

One of the major barriers to ATM is the high and uncontrolled medicine prices. Besides, lack of generic medicine awareness and utilization, high drug development costs, tariff, taxes and patent issues make the situation worse [3]. These factors are interconnected and parts of the same problem that cause lack of ATM and promote unaffordability of medicines leading to severity and chronicity of disease. Until the contributing factors influencing the outcome are understood, we will continue to struggle to offer solutions because of lack of comprehensive situation analysis.

Medicines are integral to healthcare system. The access to affordable medicines is the backbone for treating illness. The high, uneven and unregulated medicine prices have raised global concerns, especially in low and middle income countries (LMICs). Rise of newer diseases has created further complexities for the medicine affordability. A mix of institutions regulates the medicine pricing globally, but in many LMICs the health sector lacks the capacity to control the spiraling prices of medicines.

An effective management of high medicine prices will make the medicines accessible and affordable to all and play a role in patient's economy. Therefore, it is of paramount need to identify the role of existing formal, Governmental and informal organizations like Non-governmental organizations (NGOs), for the control of medicine prices to ensure patient affordability. Generating practical strategies for improving the Government's role in pharmaceutical regulation, especially where the development funding is limited, is necessary. We need to identify strategies for improving 
affordability through equitable ATM particularly for marginalized and poor patients. It is equally important to identify the situations where interventions are needed to ensure medicine affordability, e.g. approaches to increase the domestic pharmaceutical production, through investment and promotion; mechanisms of decreasing the utilization of branded medicines or high priced imported generics; ways to improve manufacture and availability of generic medicines especially in public sector.

Therefore, in 2015, the international community adopted the Sustainable Development Goals (SDGs), to "ensure healthy lives and promote well-being for all at all ages" and the achievement of universal health coverage. The Health and Human Rights Resource Guide focuses on the provision of access to affordable EM [4, 5]. In the past few decades, the SDGs and other international declarations in scientific world have changed the scenario of the ATM but still about two billion people face the barriers in ATM globally [6-8].

The ATM means "the timely use of services according to needs" [9]. In addition, access is not merely availability; it comprises physical access, which is often affected by travel costs and time; cultural access often involving gender and minority issues; and financial access including prices and ability to disburse. "On the ground" barriers exist such as market failure, corruption, nonexistent health human resources and infrastructure, and the lack of local and international political will [10]. Therefore, barriers to access are multiple, cost and non-cost.

World Health Organization (WHO) set a target of $80 \%$ availability of the affordable EM, in both public and private facilities. But in the formal sector of LMICs, average availability of medicines was found to be $35 \%$ in public facilities and $66 \%$ in the private sector [11]. Many patients, especially the poor, still rely on the informal sector for their health care needs including medicines.

Policy reforms and approaches adopted continue to be operational to address poor ATM in LMICs and according to bibliometric survey 648 publications have been published on ATM in LMICs between 2003 and 2009 [12], but the efforts seem to have only partially improved the ATM for poor.

To ensure improved ATM, it is required to evaluate the current programs and develop comprehensive interventions. We need to ensure that the current pharmaceutical policies or programs are effective, valid, sustainable and monitorable. The health outcome evaluators are required to know and understand how and why the intervention is designed, how it works and what activities of the program have the greatest impact on health outcomes. For this a theory-driven process of intervention design and evaluation is felt to be the best.

\section{What is theory of change (TOC)?}

Theory-driven approach to program evaluation can be traced back to the 1930s, with development in 1950s and 1980s [13]. The basic tenet is that understanding the theory underlying a program approach is necessary to understand how it works. The TOC was developed organically to, influence the program evaluation by theorists in social change [14].

The TOC is 'a theory of how and why an initiative works' which can be empirically tested by measuring indicators for every expected step on the hypothesized causal pathway to impact. It is developed in collaboration with stakeholders and modified throughout the intervention development and evaluation process through an 'ongoing process of reflection to explore the change and how it happens'. It is visually represented in a TOC map which is a graphic representation of the causal pathways through which an intervention is expected to achieve its impact within the constraints of the setting in which it is implemented (Figure 1).

\section{TOC and ATM}

The issue around ATM is intrinsically multifaceted, with several interrelated components, delivered at multiple levels. This complexity makes it difficult for health evaluators to evaluate ATM program interventions easily. Therefore, using ToC may help in the step-by-step evaluation. TOC is an approach which describes how a program brings about specific impact through a logical sequence of outcomes and strategies [15]. Generally, TOC is used to design, implement and evaluate complex interventions of any program or a project. We recommend utilizing the "TOC", with the impact on "to increase ATM."

While developing the ToC the backward mapping approach is used, where it starts mapping with the impact and then maps the required process of change, the outcomes and the strategies required to achieve the impact [16]. It is well-defined subsequently.

\section{Components of the TOC}

\section{Barriers to ATM}

We have elaborated the main causes impeding ATM. This lays the foundation for the change by addressing these constraints. The barriers are classified into six broad categories (Figure 1).

\section{Strategies}

These are approaches which with effective implementation can bring about positive changes in the outcomes. For example, increase in the physical, financial and social resources is a strategy designed to achieve the outcome of "Enough health-related physical and financial resources are available." Each strategy is consistent with the current problem and having promising results. 

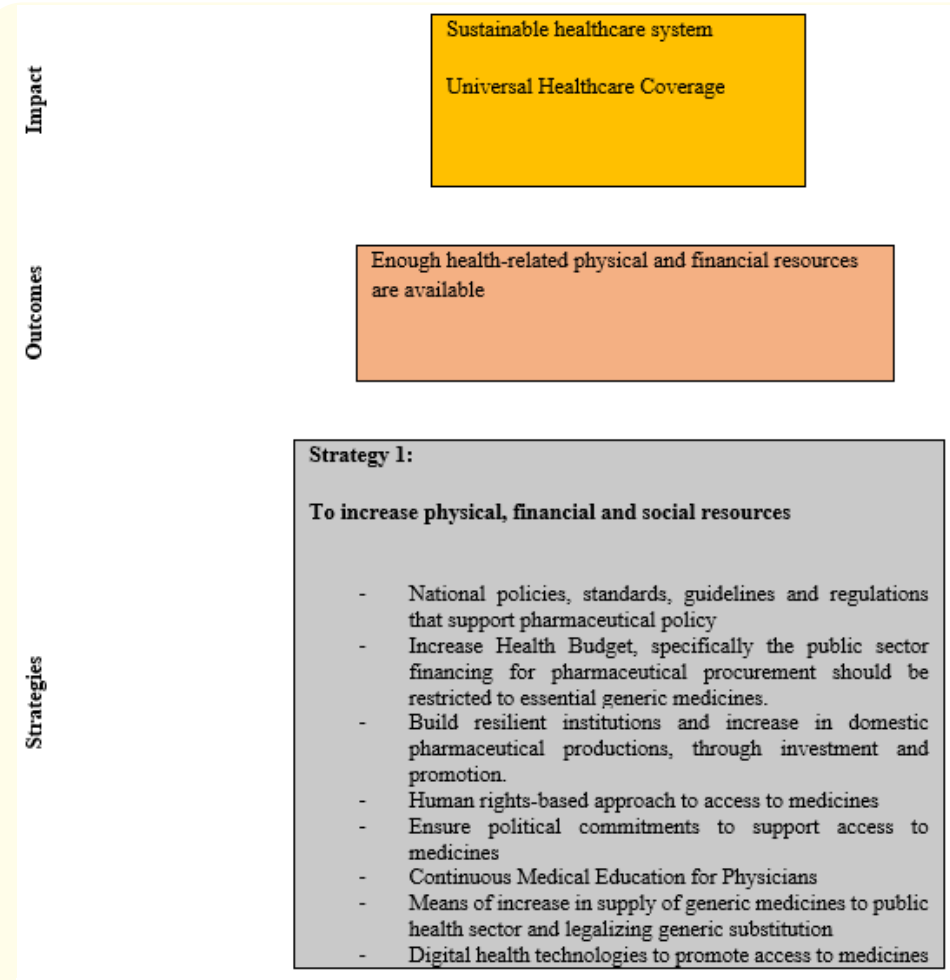

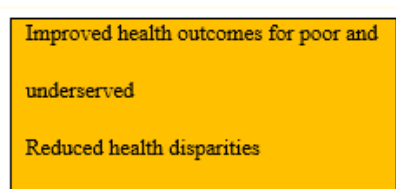

Improved access to medicines for poor and underserved people

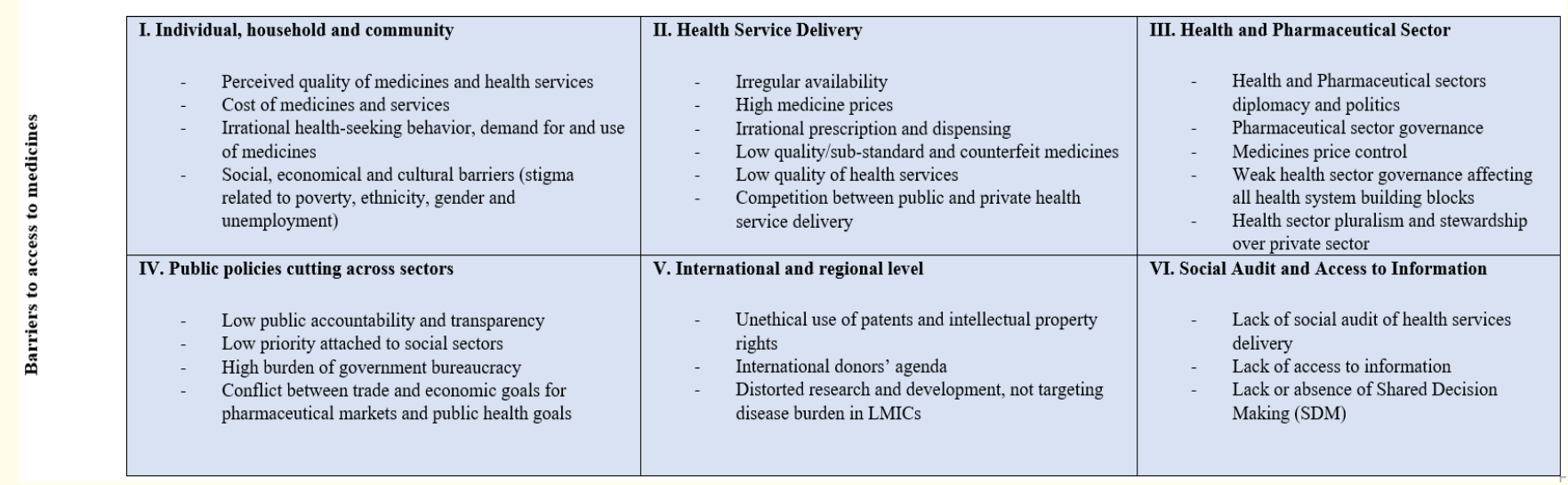

Figure 1

\section{Measures of Successful Strategy Implementation}

We propose two broad strategies and under each strategy the measures are defined for the successful implementation of strategies. Implementation of each measure is required by the stakeholders to ensure the change in outcomes.

\section{Outcomes and Impact}

The stakeholders should invest resources and do critical evaluation to ensure that the following outcomes and impacts are achieved.

\section{Outcomes Areas}

- Enough health-related physical and financial resources are available

- Improved ATM for poor and underserved people

- Impact Areas
- Ensuring sustainable healthcare system and universal healthcare coverage

- Improved health outcomes for poor and underserved people by reduction in health disparities

\section{Evaluation of the TOC}

In the implementation of the strategies to ensure ATM, it is important that the stakeholders critically continue to evaluate the programs or initiatives to determine whether the intended results are achieved. Additionally they should track whether strategies are working or need any modification. The WHO and health activists have been pressuring global pharmaceutical companies to launch more ATM initiatives in LMICs and have succeeded but regretfully, few researchers have the idea how these initiatives are able to impact [17]. The Boston University Department of Global Health 
discovered that among 102 companies only seven published evaluations and none of them were rated to be of high quality [17].

It is well known that any change is resisted and complex conditions and systems; "failure" is a natural part of the learning process. Therefore, if a selected strategy or initiative does not achieve the desired threshold of change over the time, then the following issues should be considered:

- Is the organization the right one to carry out the implementation of the strategies?

- Were the measures adopted to improve the conditions and capacity the right ones to implement the strategy successfully?

- Was the strategy appropriate for addressing the issues?

- Was the strategy implemented with commitment over a sufficient period of time in order for change to occur?

- Were the amount and duration of the investment adequate to achieve the desired outcome?

Hence this paper is drafted with the aim to highlight the need for evaluation of a complex adaptive systems approach in improving ATM, and offer strategies of how the problems around ATM should be addressed by defining the underlying causes/barriers. Literature has been reviewed to prescribe suitable measure to draft theory-driven approaches towards ATM [18-23].

\section{Developing the to $\mathrm{C}$}

To ensure that everyone at program levels, stakeholders and the beneficiaries are well-versed and know the development of TOC, it is important to hold a workshop. The TOC workshop must be led by principal investigator to provide guidance to the workshop participants. Stakeholders/ participants are to be identified from Ministry of Health, Pharmaceutical Companies, NGOs, Civil Society Organizations (CSOs) and donor agencies.

During the workshop, the facilitator must describe the essence and rationale of the TOC and its relation in evaluating interventions around ATM. The participants must be given a time to develop/ construct the ToC based on their ground realities, challenges or the assumptions in their context. It is not mandatory to follow the TOC described in Figure 1. There are multiple templates used for the constructing TOC. The main aim of the TOC shown in Figure 1 is for illustration and example purposes only.

\section{Discussion}

Though TOC approach has been in use in the public health sector since 1999, no study has focussed on ATM. More than 62 peer reviewed papers were found in journals where only issues regarding public interventions were discussed [21].

The access to quality medicines is nested within the health system and acts as an integral and significant factor to ensure sus- tainable health coverage for all. Given this, it is important to review the literature in order the system to be analysed and to best understand how innovations and interventions will affect the ATM. For instance, a study focused on improved safety and access to resources with no clear indication towards ATM and emphasis on decreased barriers to access of TB resources $[24,25]$.

Hundreds of policies and regulations have been written, adopted and adapted without significant results. If the implementing agencies do not apply or implement the suggested cost controlling mechanism and policies, without identifying underlying barriers towards ATM, we will lose the control over soaring medicine prices in the market which will lead to further unaffordability. Therefore, it is critical to identify the root causes/ barriers as part of TOC.

\section{Barriers to access}

Barriers to ATM are numerous (Figure 1) ranging from individual level to international. Ensuring ATM is feasible by removing these barriers, and the international community and the national governments should work towards sustainable economic development mechanisms, employment creation, especially in LMICs, since research shows a positive association between per capita Gross domestic product (GDP) growth and life expectancy [26].

At the individual, household and community level we are faced with the quality and cost issues of healthcare services and the medicines. WHO reports that medicines account for $20-60 \%$ of health spending in LMICs, and up to $90 \%$ of the population in developing countries purchase medicines through out-of-pocket payments, making medicines the largest expenditure item after food [27].

Low-priced medicines should not only be made available to the poor, but also to the middle-income groups. Such arrangement has been keenly looked up to find out what happens at the household level, particularly to the poorest families. In addition, the irrational health-seeking behavior increases the patient demand for medicines purchase which in turn puts economical burden on individuals, households and the community at large [8].

At Health service delivery level irregular availability of medicines and stock outs in public sector compel the poor patients to purchase medicines from private pharmacies, where usually the medicine prices are high. Among various barriers the high medicine prices plays a critical role in high and rising health care costs in the countries especially LMICs [28].

Albendazole was approved in 1996. In 2010, its average wholesale cost was $\$ 5.92$ per day, but in 2013 , it had risen to $\$ 119.58$. The price of captopril (12.5 mg) increased by more than $2800 \%$ between November 2012 and November 2013, from 1.4 cents to 39.9 cents per pill. Similarly, the price of clomipramine ( $25 \mathrm{mg}$ ), increased from 22 cents to $\$ 8.32$ per pill, and the price of doxycycline 
hyalite (100 mg), increased from 6.3 cents to $\$ 3.36$ per pill [29]. Numerous factors may cause price increase for non-patent-protected drugs, including drug shortages, stock outs, supply disruptions, and consolidations within the generic-drug industry. These lead to decrease in market competition.

Irrational prescription and dispensing could be barrier to ATM. According to WHO, up to $50 \%$ of medicines are inappropriately prescribed or dispensed and up to $50 \%$ are used incorrectly by the patients [30]. This leads to significant wasted resources, drives the development of drug resistance and leads to poor health outcomes.

Production, sale, presence, prescription, dispense and consumption of low quality/sub-standard and counterfeit medicines could be critical in ATM. Low quality of health services in the country and the unethical competition between public and private health service delivery hampers ATM [8]. There are barriers to ATM in the health sector of each country specifically in LMICs e.g. problems in health and pharmaceutical diplomacy and politics. With changing environment, globalization and complexity of health and pharmaceutical systems, global health diplomacy is increasing and it requires technical workforce, legal knowledge, economical and pricing skills and diplomatic skills to work in the sector. Equitable health system is the outcome of strong political will and advocacy, that how to distribute health resources fairly across populations, geographic areas, and health care priorities. In order to make the advocacy successful it is required that national actors perform multilateral lobbying efforts and attract the foreign assistance to support their domestic pharmaceutical industry.

Weak and inefficient health sector governance affects health system especially ATM e.g. in developing economies like the Middle East and North African countries, where the pharmaceutical sector is relatively unregulated, and the extent of regulation depends on level of income, policies and degree of inclusion of the healthcare system in the national vision. This can also affect the availability and affordability of medicines [31]. It is apparent that leadership and governance play important role in preventing corruption and sale of drugs in black markets. Strictly enforceable regulation serves to mitigate the problem of counterfeits and substandard medicines.

At policy level, problems of negligence negatively affect ATM, like absence or impractically of public accountability and transparency, sluggishness and bureaucratic hurdles [8]. Unavailability and lack of access to reliable thorough public information on the safety, efficacy, prices, patent status, sources of investment, and costs of research and development ( $R$ and $D$ ) in developing lifesaving medicines can convolute the scenario. The governments should reveal the information on pharmaceutical development, including $\mathrm{R}$ and D costs and the public procurement [32].
At the international and regional level several barriers impede ATM e.g. unethical use of patents and intellectual property rights (IPR), unclear R and D, and non targeting disease burden in LMICs.

Access to information being the human right, it plays crucial role in healthcare services. Social accountability and audit [33] and stringent information systems play a critical role in health services delivery, drug supply management and avoidance of stock-outs - a central tenet. To ensure ATM, shared decision making (SDM) initiative must be in place to ensure improvement in prescribing and dispensing practices as well as for supporting adherence to drug regimens, price control and patient satisfaction. Given the factors limiting access to affordable medicines are manifold and intertwined, pragmatic strategies and integrated measures are required to ensure access to EM. We suggest two strategies to tackle this problem.

\section{Strategy one}

To increase physical, financial and social resources

For lack of ATM for poor and marginalized populations in LMICs, measures and solutions to ensure increase in physical, financial and social resources are needed. To achieve this it is recommended that the governments should adopt policies, standards, guidelines and regulations that support the pharmaceutical policy. It should increase the health budget, specifically the public sector financing for pharmaceutical procurement which should be restricted for purchasing EM of generic type. It is important that the government adopts a comprehensive program to control the public resources and ensure ATM. For example in Chad the budget allocated for medicines leaks before it gets to the ultimate beneficiary and this leakage rate is 99 percent [34]. In such situations allocating additional public money for medicine cannot improve poor people's access to quality medicines [34].

Many governments purchase high cost originator medicines and non essential and non generic medicines. To facilitate ATM and help health systems achieve positive, measurable, and sustainable health impact, government should identify the institutional weaknesses and put a mechanism for building effective and resilient health care institutions [35].

ATM is well founded and described in international law for example in 1946 Constitution of the WHO and the 1948 Universal Declaration of Human Rights (UDHR) which expressly recognize the right to health $[36,37]$. The WHO, resolutions of the Human Rights Council, and the Doha Declaration on TRIPS and Public Health reaffirm access to EM as a human right that must be available "for all." Local state and not-state actors are responsible to ensure ATM for all, for instance, pharmaceutical companies have human rights responsibilities described by the former UN Special Rapporteur on the Right to Health, including the duty to take all 
reasonable measures to make new medicines "as available as possible" for those in need. Additionally, the UN Guiding Principles on Business and Human Rights, which were unanimously endorsed by the UN Human Rights Council in 2011, obliges the private sector to take responsibility for violations of human rights related to access to medicines [38].

Ensure political commitments to support ATM, control medicine prices and ensure that all have access to the right medicine at the right time and the right price. Continuous medical education through educational meetings, workshops and seminars to improve the practice of health professionals need to be organized. These pave the way for continuous improvement in the medical field and eliminate the barriers to ATM [39].

Supply of generic medicines in public health sector, legalizing generic substitution and digital health technologies to promote ATM need to be introduced. For example, Beijing legalized the sale of prescription drugs through online platforms; which can provide improved access to remote places and lower-tier cities. To equalize access to health care for the whole nation, the online sales need to be promoted [40].

\section{Strategy two}

To decrease medicine prices and promote access

Universal ATM is the main goal of WHO and its member states as part of their medicine policy [41]. In order to achieve this, reforms in the national budget by decreasing tariffs, duties and taxes on medicines and health commodities need to be done. The Ministry of Health at national level should work with other healthcare stakeholders to lobby and do the advocacy to waive / decrease the tariffs, duties and taxes on health devices especially on EM. If the government is unable or unwilling to waive / decrease the import tariffs, duties or taxes, the revenue generated from tariffs or taxes of medicines or health devices must be utilized for purchasing EM. This will lead to positive competition and will help ATM. Waiving the government imposed barriers is most important step in improving ATM.

Adopting compulsory licensing especially on high priced patented EM can maximize ATM and play an important role in improving public health. The governments must adopt compulsory licensing to encourage ATM, promote competition and restrain soaring prices. Government can be the patent holder. As a corporate social responsibility it can award voluntary licenses to other parties to ensure access to EM. For example the Malaysian government made the hepatitis C medicine (Sofosbuvir) at an affordable price through compulsory licensing $[42,43]$. There are chances for price reductions worldwide; however it requires relentless efforts like the Malaysian government [43].
Means of reduction in consumption of branded or high priced imported generics have to be found through efficient custom systems and increasing awareness of public and healthcare activists. Explore the causal link between affordability and high medicine prices.

It has been suggested that the medicine development process should be separated as of research financing from end-product prices. This model was successful in not-for-profit drug-development efforts that build the affordability. For example, with $\$ 290$ million from public funds and philanthropic contributions, the Drugs for Neglected Diseases Initiative (DNDi) put 26 candidate products into the development pipeline and brought six to market in 10 years; because the research costs were already covered, DNDi's products can be sold for approximately the cost of production [44].

Establishment of National EM System and monitoring of medicine availability, prices and affordability can go a long way in bringing the reforms. Uncontrolled and soaring medicine prices are a global concern. To eliminate unnecessary costs and regulate medicine prices it is important to establish a nationwide system. For example in China for medicine price control and ensuring its access a National EM System (NEMS) was established [45]. To ensure the implementation of this, medicine policy implementation and performance of healthcare providers it is important hence rigorous monitoring and control system to track medicine prices in the supply chain is needed $[46,47]$.

Implementation of evidenced-based treatment approaches have to be encouraged. Evidenced-based approach for health care systems is to be established with aim of healthcare expenditure control. This has been supported by research that the implementation of evidenced-based treatment can decrease the treatment-related cost for example cost borne by physician or hospital, diagnosis and transportation [48]. Thus money will be spared which can be better utilized to procure medicines and will widen the scope of access.

Controlling unfair trade practices and out-licensing of medicines need to be practiced. Multilayered strategies and measures such as compulsory licensing for patented medicines, adopting voluntary licensing agreements, global purchasing mechanisms, tiered pricing, waiving tariffs, domestic production of high-quality affordable generics, generic substitution, rational use of medicine can positively contribute to ATM [49,50]. In addition control of illegal price advertising such as hidden fees, surcharges, predatory pricing and other malpractices in the marketplace can ensure ATM. Overall, the state, non-state actors and other stakeholders should collaborate and commit to tailor a pharmaceutical pricing policy that respects the uniqueness of an individual market and its economics capacity [31] 
Impact

The availability of medicine (AOM) and ATM are the desired outputs of a program intervention. Our aim is to ensure the positive impact of ATM on healthcare system for the patient welfare. Hence it is important that the barriers in the path should be identified and overcome. The program outputs need to be evaluated to ensure that enough health-related physical and financial resources are available at the country level. This will ensure that sustainable healthcare system is in place for universal healthcare coverage. It will bring about the improved access to medicines for poor and underserved people and reduce health disparities.

\section{The path forward}

We have to acknowledge that stringent program evaluation will ensure success of ATM. The interventions should be evaluated using TOC and finding the casual pathway both at national and international levels.

Introducing different programs are unlikely to have a large impact. Instead, political commitment, transparency and establishing resilient institutions can be leveraged to improve ATM.

Building on the existing work, we should further explore interventions during our march, particularly, greater focus on medicine prices must be drawn and should be a key priority and top agenda.

Improvements are required to investigate and address the malpractices in pharmaceutical procurement that jeopardise the quality and affects the medicine prices and hampers access.

The structure of pharmaceutical system is complex in different countries, therefore continuing reforms are necessary for standardization of ATM indicators, for example demand, purchase, utilization, payment and classification based on the evaluation criteria (price, availability, affordability, geographic accessibility, patient access acceptability and accommodation).

\section{Financial support}

None.

\section{Conflicts of Interest}

The authors report no conflicts of interest related to this study.

\section{Acknowledgements}

None.

\section{Bibliography}

1. Bashaar M., et al. "Efficacy of international approaches to medicine price regulation and control: A scoping review". Journal of Applied Pharmaceutical Science 7.04 (2017): 227241.

2. Bigdeli M., et al. "Medicines in health systems: advancing access, affordability and appropriate use". (2014).
3. Hausmann-Muela S., et al. "Health-seeking behaviour and the health system response". Disease Control Piroirities 14 (2003).

4. Kieny MP and Evans DB. Universal health coverage (2013).

5. Barredo L., et al. "Ensure healthy lives and promote well-being for all at all ages". UN Chronicle 51.4 (2015): 9-10.

6. Access to Medicine Foundation: "The Access to Medicine Index: Methodology 2015”. (2016).

7. Bashaar M., et al. "40th anniversary of essential medicines: a loud call for improving its access". Generics and Biosimilars Initiative Journal 6.4 (2017).

8. Bigdeli M., et al. "Access to medicines from a health system perspective". Health Policy and Planning 28.7 (2012): 692704.

9. Peters DH., et al. "Poverty and access to health care in developing countries". Annals of the New York Academy of Sciences 1136.1 (2008): 161-171.

10. Taylor DW and CIM F. "Pharmaceutical Access in Least Developed Countries: on-the-ground barriers and industry successes". Cameron Institute (2010): 182.

11. Cameron A., et al. "Medicine prices, availability, and affordability in 36 developing and middle-income countries: a secondary analysis". The lancet 373.9659 (2009): 240-249.

12. Adam T., et al. "Trends in health policy and systems research over the past decade: still too little capacity in low-income countries". PloS One 6.11 (2011): e27263.

13. Chen H. "Theory-driven evaluation: A comprehensive perspective". Thousand Oaks, Calif (1990).

14. James C. "Theory of change review". Comic Relief (2011).

15. Vogel I. "Review of the use of 'Theory of Change'in international development". Department for International Development (2012).

16. Anderson AA. "The community builder's approach to theory of change: A practical guide to theory development". Aspen Institute Roundtable on Community Change (2006).

17. Olson DJ. "Most access-to-medicine initiatives are poorly evaluated". here's one effort to change that 9 (2017).

18. Kleinman A. "Four social theories for global health". The Lancet 375.9725 (2010):1518-1519.

19. De Silva MJ., et al. "Theory of Change: a theory-driven approach to enhance the Medical Research Council's framework for complex interventions". Trials 15.1 (2014): 267.

20. Thomson H and Thomas S. "Developing empirically supported theories of change for housing investment and health". Social Science and Medicine 124 (2015): 205-214.

21. Breuer E., et al. "Using theory of change to design and evaluate public health interventions: a systematic review". Implementation Science 11.1 (2015): 63. 
22. Javadi D and Bigdeli M. “Examples of complexity approaches to access to medicines in the existing literature". (2014).

23. Maini R., et al. "How to and how not to develop a theory of change to evaluate a complex intervention: reflections on an experience in the Democratic Republic of Congo". BMJ Global Health 3.1 (2018): e000617.

24. Anderson RA and McDaniel Jr RR. "Managing health care organizations: where professionalism meets complexity science". Health Care Management Review 25.1 (2000): 83-92.

25. Plsek PE and Wilson T. "Complexity science: complexity, leadership, and management in healthcare organisations". British Medical Journal 323.7315 (2001): 746-749.

26. Barro RJ. "Determinants of economic growth: A cross-country empirical study". National Bureau of Economic Research (1996).

27. WHO. "WHO guideline on country pharmaceutical pricing policies". World Health Organization (2015).

28. Smith S., et al. "Income, insurance, and technology: why does health spending outpace economic growth?" Health Affairs 28.5 (2009): 1276-1284.

29. Colliver V. "Prices soar for some generic drugs". SFGate. (2014).

30. WHO. "World Health Organization Google Scholar20042007 countries at the core". (2004).

31. Rida NMA and Ibrahim MIM. "Pricing strategies for pharmaceuticals in developing countries: what options do we have?" Gabi Journal-Generics and Biosimilars Initiative Journal 6.1 (2017): 4-6.

32. Moon S. "Powerful ideas for global access to medicines". New England Journal of Medicine 376.6 (2017): 505-507.

33. Puri M and Lahariya C. "Social audit in health sector planning and program implementation in India". Indian Journal of Community Medicine 36.3 (2011):174-177.

34. Gauthier B and Wane W. "Leakage of public resources in the health sector: an empirical investigation of Chad". Journal of African Economies 18.1 (2008): 52-83.

35. Usaid. Promoting The Rational Use Of Medicines, Systems for Improved Access to Pharmaceuticals and Services (SIAPS) (2015).

36. Lauterpacht H. "The Universal Declaration of Human Rights". Brit YB Int'l L 25 (1948): 354.

37. WHO. "Preamble to the Constitution of the World Health Organization asadopted by the International Health Conference". New York, 19-22 June, 1946; signed on 22 July 1946 by the representatives of 61 States (Official Records of the World Health Organization, and entered into force on 2 (1948): 100.
38. Ruggie J. "Report of the Special Representative of the Secretary-General on the Issue of Human Rights and Transnational Corporations and Other Business Enterprises: Guiding Principles on Business and Human Rights: Implementing the United Nations 'Protect, Respect and Remedy'Framework". Netherlands Quarterly of Human Rights 29.2 (2011): 224-253.

39. Davis D., et al. "Impact of formal continuing medical education: do conferences, workshops, rounds, and other traditional continuing education activities change physician behavior or health care outcomes?" Jama 282.9 (1999): 867-874.

40. South China Morning Post. China removes barriers to affordable medicine as health reform gathers pace (2015).

41. WHO. "World health statistics World Health Organization". (2015).

42. Loh FF. "Malaysia wins award for access to affordable hepatitis C medicine". (2018).

43. Wirtz VJ., et al. "Essential medicines for universal health coverage". The Lancet 389.10067 (2017): 403-476.

44. Maxmen A. "Busting the billion-dollar myth: how to slash the cost of drug development". Nature 536.7617 (2016).

45. Song Y., et al. "Effects of the National Essential Medicine System in reducing drug prices: an empirical study in four Chinese provinces". Journal of pharmaceutical policy and practice 7.1 (2014): 12.

46. Xiphu L and Mpanza N. "Medicine prices survey in the Gauteng province in South Africa". National Department of Health (2004).

47. Kotwani A. "Tracking Medicine Prices in the Supply Chain". Economic and Political Weekly 48.52 (2013): 105.

48. Warner BW., et al. "An evidenced-based clinical pathway for acute appendicitis decreases hospital duration and cost". Journal of Pediatric Surgery 33.9 (1998): 1371-1375.

49. Waning B., et al. "A lifeline to treatment: the role of Indian generic manufacturers in supplying antiretroviral medicines to developing countries". Journal of the International AIDS Society 13.1 (2010): 35.

50. Hoen Et., et al. "Driving a decade of change: HIV/AIDS, patents and access to medicines for all". Journal of the International AIDS Society 14.1 (2011): 15.

Volume 3 Issue 10 October 2019

(C) All rights are reserved by Mohammad Bashaar and Tafseera Hashemi. 